\title{
Annual variation of strato-mesospheric carbon monoxide measured by ground-based Fourier transform infrared spectrometry
}

\author{
V. Velazco ${ }^{1}$, S. W. Wood ${ }^{2}$, M. Sinnhuber ${ }^{1}$, I. Kramer ${ }^{3}$, N. B. Jones ${ }^{4}$, Y. Kasai ${ }^{5}$, J. Notholt ${ }^{1}$, T. Warneke ${ }^{1}$, \\ T. Blumenstock ${ }^{3}$, F. Hase ${ }^{3}$, F. J. Murcray ${ }^{6}$, and O. Schrems ${ }^{7}$ \\ ${ }^{1}$ Institute of Environmental Physics University of Bremen, Bremen, Germany \\ ${ }^{2}$ National Institute of Water and Atmospheric Research Ltd, Lauder New Zealand \\ ${ }^{3}$ Institute of Meteorology and Climate Research, Forschungszentrum Karlsruhe and Univ. Karlsruhe, Karlsruhe, Germany \\ ${ }^{4}$ Department of Chemistry University of Wollongong, Wollongong, Australia \\ ${ }^{5}$ Global Environment Division National Institute of Information and Communications Technology (NICT), Tokyo, Japan \\ ${ }^{6}$ Department of Physics and Astronomy, University of Denver, Denver, Colorado, USA \\ ${ }^{7}$ Alfred Wegener Institute for Polar and Marine Research, Bremerhaven, Germany
}

Received: 5 May 2006 - Published in Atmos. Chem. Phys. Discuss.: 28 July 2006

Revised: 13 December 2006 - Accepted: 20 February 2007 - Published: 26 February 2007

\begin{abstract}
We present long-term time-series of stratomesospheric $\mathrm{CO}$ vertical columns measured from stations located in Antarctica, mid-latitudes and the Arctic, covering the period from 1997-2005. The instrument and the measurement technique allows the separation of tropospheric and strato-mesospheric contributions to the $\mathrm{CO}$ column, therefore providing information on the chemistry and dynamics both at low and high altitudes. Data from polar stations show a similar annual variability of strato-mesospheric $\mathrm{CO}$ with a strong maximum in late winter and spring. A small enhancement in late summer for some stations, which we call the "summer bulge", can be seen occasionally. Generally, the mid-latitude stations show no significant annual variability of strato-mesospheric CO columns. Measurements were compared with a two-dimensional chemistry-transport model of the middle atmosphere. The annual and latitudinal variations of $\mathrm{CO}$ are reproduced well by a model run including thermospheric CO. Comparison with two model scenarios show that the polar winter maximum is due solely to downward transport of thermospheric $\mathrm{CO}$, while $\mathrm{CHO}_{\mathrm{x}}$ chemistry in the stratosphere could probably contribute to the summer maximum.
\end{abstract}

\section{Introduction}

The high latitude regions have a larger seasonal variation in atmospheric properties than anywhere else on earth (Notholt

Correspondence to: V. Velazco

(voltaire@iup.physik.uni-bremen.de) et al., 1997). To study this variation, we use carbon monoxide (CO), which is an excellent tracer for global transport and air mass descent rates in the polar stratosphere and lower mesosphere. Its importance as an indicator of vertical transport in the mesosphere was highlighted in results from ground-based measurements e.g. Künzi and Carlson (1982). At altitudes of about $50 \mathrm{~km}$, the photochemical lifetime of $\mathrm{CO}$ is about 7 days, which is comparable to the vertical and horizontal advection time scales at these altitudes (Dupuy et al., 2004; Solomon et al., 1985).

The primary source of carbon monoxide in the upper mesosphere and lower thermosphere is the photolysis of carbon dioxide. In the stratosphere, $\mathrm{CO}$ is produced through the oxidation of atmospheric methane, but $\mathrm{OH}$ rapidly destroys it through oxidation. This reaction acts as the main sink of CO. This process does not take place during the polar night, since $\mathrm{OH}$ is produced by reactions involving photolysis, e.g. of $\mathrm{H}_{2} \mathrm{O}$, and since the concentration of $\mathrm{OH}$ diminishes rapidly during polar night. Carbon monoxide follows the meridional circulation towards the winter hemisphere polar night region. The consecutive downward motion induces a sharp gradient in the $\mathrm{CO}$ concentrations down to the stratosphere (Solomon, et al., 1985). In summer, uplifting of air masses with low CO content takes place. Solomon et al. (1985) predicted that very large abundances should accumulate in the polar night mesosphere because of the absence of photochemical destruction processes.

Previous ground-based measurements of mesospheric $\mathrm{CO}$ were shown in pioneering works such as that of Künzi and Carlson (1982); Clancy et al. (1982); Zander et al. (1981); Farmer et al. (1980); Goldsmith et al. (1979); etc. However,

Published by Copernicus GmbH on behalf of the European Geosciences Union. 
there is a lack of long term ground-based observations of strato-mesospheric CO in the literature. Recently, satellites have been able to measure high-altitude $\mathrm{CO}$ (e.g. LopezValverde et al., 1993; Dupuy et al., 2004; Clerbaux et al., 2005). But until now, the longest reported time series of $\mathrm{CO}$ in the upper atmosphere was done by Forkmann et al. (2003) over the Onsala Space laboratory, Sweden $\left(57.4^{\circ} \mathrm{N}, 12^{\circ} \mathrm{E}\right)$. The time series spanned from September 2000 to September 2002.

Strato-mesospheric $\mathrm{CO}$ has been measured for the first time using ground based FTIR spectrometry by Kasai et al. (2005). However, measurements for only 2 years were presented. This study supports the work of Kasai et al. (2005) but we present longer time series measurements from the northern and southern polar regions and the mid-latitudes. This allows us to have a better idea of the seasonal variation of strato-mesospheric $\mathrm{CO}$ and confirm that the current ground-based FTIR instruments and retrieval procedures are able to exploit the information on strato-mesospheric $\mathrm{CO}$ from existing spectra. Furthermore, current measurements provide very little evidence on the reversal of the accumulation of $\mathrm{CO}$ in the mesosphere brought about by the meridional circulation. By showing measurements from both the northern and southern hemispheres, we verified this reversal.

\subsection{Instruments}

Ground- based measurements of solar absorption spectra were taken from three Arctic stations ( $\mathrm{Ny}$ Alesund $79^{\circ} \mathrm{N}$, Kiruna $68^{\circ} \mathrm{N}$ and Poker Flat $65^{\circ} \mathrm{N}$ ), one Antarctic station (Arrival Heights $78^{\circ} \mathrm{S}$ ) and two mid-latitude stations (Bremen, Germany $53^{\circ} \mathrm{N}$ and Lauder, New Zealand $45^{\circ} \mathrm{S}$ ). All stations are equipped with Bruker $120 \mathrm{HR}$ Fourier transform spectrometers except for Arrival Heights (Bruker 120 M) and Bremen (Bruker 125 HR from June 2004). Automatic solar trackers allow for the continuous measurements of direct sunlight from the ground. For the polar stations, measurements are limited by the polar night. Solar spectra in $\mathrm{Ny}$ Alesund can be recorded between March and early October. In Kiruna, the polar night is between early December and mid January. At the Arrival Heights station in Antarctica, the polar night is between late April and mid August. Measurements in Poker Flat are possible between early February and mid October.

\subsection{Retrieval of strato-mesospheric CO}

It is possible to derive vertical profiles of $\mathrm{CO}$ with a maximum resolution of about $4 \mathrm{~km}$ up to approximately 16 to $20 \mathrm{~km}$ (Velazco et al., 2005). Above $20 \mathrm{~km}$, the vertical resolution becomes very coarse that useful information cannot be derived, i.e. the individual layers of the stratosphere and mesosphere cannot be separated. This is due to the limited information content arising from the nature of the retrieval method. However, information can still be gained by con- sidering these inseparable layers of the atmosphere as one partial column layer, and retrieving the $\mathrm{CO}$ concentration in this layer.

Partial columns of $\mathrm{CO}$ were retrieved from the absorption lines in two steps. First, volume mixing ratio (VMR) profiles from the surface up to about $100 \mathrm{~km}$ were retrieved. The profiles were then converted into number densities using heighttemperature-pressure profiles and integrated to yield partial columns. The pressure and temperature profiles necessary for the forward model were obtained from balloon sondes that were launched daily from the stations. Above the altitude limits of the sondes (approximately $30 \mathrm{~km}$ ), standard pressure and temperature profiles were taken. In Kiruna, pressure and temperature profiles were taken form NCEP (Kanamitsu, 1989).

The program used for the retrieval of CO VMR profiles for Ny Alesund, Poker Flat, Bremen, Lauder and Arrival Heights is SFIT-2 version 3.8 (Spectral Least Squares Fitting Program) developed at NASA Langley Research Center and the National Institute for Water and Atmospheric Research in New Zealand. For further descriptions see e.g. Rinsland et al. (1998). The main element of the software is the forward model that creates a synthetic spectrum from a simulated atmosphere, which is divided into 29 layers ( 45 for Kiruna). It then fits the measured spectrum and the synthetic spectrum using the optimal estimation method (Rodgers, 2000).

The program used to retrieve the Kiruna data is PROFFIT 9 developed by Hase (2002). The code is capable of handling general covariance matrices. For the efficient construction of simplified empirical covariances, the formalism described by Tikhonov and Philips is used (Hase et al., 2004). An intercomparison between SFIT2 and PROFFIT has shown excellent agreement of profiles and total column amounts. The averaging kernels are consistent and the results are compatible for independently chosen constraints (Hase et al., 2004).

$\mathrm{CO}$ spectra were analyzed in the $\mathrm{CO}$ micro-windows based on the previous work of Rinsland et al. (1998). For this study, the micro-windows used are $2057.70-2057.91 \mathrm{~cm}^{-1}$, $2069.55-2069.72 \mathrm{~cm}^{-1}$, and $2157.40-2159.20 \mathrm{~cm}^{-1}$. An additional window, $2140.4-2141.40 \mathrm{~cm}^{-1}$, and a broader region in one of the standard micro-windows, i.e. 2153.2$2160.0 \mathrm{~cm}^{-1}$ were used for the Kiruna retrievals. For all stations, the HITRAN2k line list plus updates to 2001 (Rothman et al., 2003) was used. Typical averaging kernels for the retrievals in Ny Alesund and Poker Flat are shown in Fig. 1. The figure shows that the 2 partial columns from $0.2-18 \mathrm{~km}$ and from $18 \mathrm{~km}$ to $85 \mathrm{~km}$ can be separated. An example from $\mathrm{Ny}$ Alesund shows that the kernel for the $18 \mathrm{~km}$ to $85 \mathrm{~km}$ is not perfect, i.e. it does not have a maximum of 1.0. Furthermore, the stratospheric columns and the mesospheric columns are not separable, thus we provide the measurements as strato-mesospheric columns. The kernels calculated for Poker Flat are closer to unity compared to the ones for Ny Alesund. The factors that contribute most to the shape of the averaging kernels are; the optical path 
difference, the solar zenith angle, the a-priori covariance matrix, the a-priori profile and the signal to noise ratio. The kernels for Poker Flat were calculated with a slightly lower a-priori constraint above $18 \mathrm{~km}$ (a-priori uncertainty corresponding to $55 \%$, compared to $20 \%$ for Ny Alesund) and a conservative estimate of 100 for the signal to noise ratio (Kasai et al., 2005).

For the strato-mesospheric CO partial columns above $24 \mathrm{~km}$ Kasai et al. (2005) reported an error of $15 \%$. This error consists of random error terms including: measurement error of $5.2 \%$, smoothing error of $8.2 \%$ and temperature error of $1 \%$. The forward model error of $5 \%$ was been treated as a systematic error. In comparison, the total column error was reported to be less than 5\%. For this study, we estimate the partial column ( $18 \mathrm{~km}-$ top of atmosphere) errors to be between $8.3 \%$ and $9.3 \%$.

\subsection{The chemical transport model}

The model used is a global two-dimensional photolysis, chemistry and transport model of the stratosphere and mesosphere. It is a coupled chemistry-dynamics model which combines the THIN AIR meteorological code (Kinnersley, 1996) and the SLIMCAT chemistry code (Chipperfield, 1999). Temperature, pressure and wind fields are calculated by the THIN AIR code on isentropic surfaces from the bottom up to $\sim 100 \mathrm{~km}$ with a vertical spacing of about $3 \mathrm{~km}$.

The model has a horizontal resolution of about $9.5^{\circ} \mathrm{ex}-$ tending from pole to pole in 19 evenly spaced latitude bins. The chemistry module uses JPL-2003 photochemistry data (Sander et al., 2003). Though the SLIMCAT model is not appropriate for the troposphere, it is applied to the entire vertical range of the model. Heating rates are calculated in the THIN AIR module, using $\mathrm{O}_{3}, \mathrm{NO}_{2}$ and $\mathrm{CH}_{4}$ values provided by the chemistry module. $\mathrm{CO}_{2}$ is also used to calculate heating rates, however, as this is very long-lived in the stratosphere and mesosphere, it is not accounted for in the chemistry code. In the past, the model has been used for a number of studies concerning the composition of the middle atmosphere (Sinnhuber et al., 2003; Chipperfield and Feng, 2003). Tropospheric sources of chlorine, bromine and fluorine compounds as well as greenhouse gases like $\mathrm{CH}_{4}, \mathrm{~N}_{2} \mathrm{O}$ and $\mathrm{CO}_{2}$ are based on the WMO A1 scenario (WMO, 2002, 2003).

Model runs started from 1988, and run to 2005. For this study, two model runs were carried out. The "base" scenario uses the original SLIMCAT chemistry which does not contain $\mathrm{CO}_{2}$. This means that $\mathrm{CO}$ is produced solely from $\mathrm{CH}_{4}$ oxidation. In a second model run, called "thermospheric", $\mathrm{CO}$ in the uppermost model box is fixed to the $\mathrm{CO}_{2}$ value. This means that $\mathrm{CO}_{2}$ is transported unchanged into the thermosphere, where it is transferred into $\mathrm{CO}$ immediately. $\mathrm{CO}$ will then be transported down into the mesosphere and stratosphere during polar winter; after polar sunrise, $\mathrm{CO}$ will react with $\mathrm{OH}$, re-forming $\mathrm{CO}_{2}$ in a couple of days.

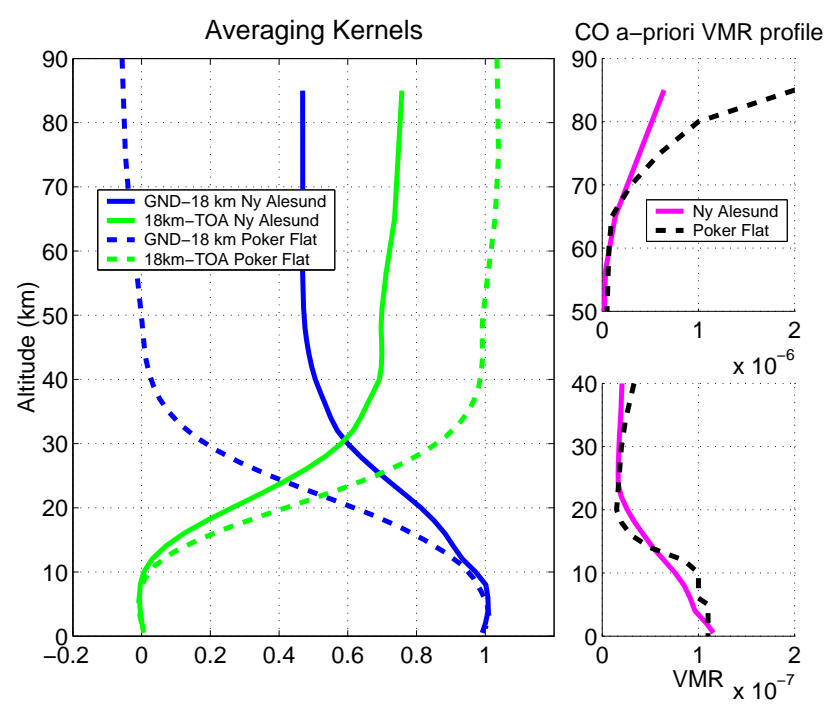

Fig. 1. (Left) Typical averaging kernels for the retrieval of $\mathrm{CO}$ for Ny Alesund (solid curves) and Poker Flat (dashed curves). The kernels from $18 \mathrm{~km}$ to the top most layer of the retrieval are shown by the blue curves. The green curves are the averaging kernels for the retrieval of the CO column from the ground to $18 \mathrm{~km}$. (Calculated for Ny Alesund for solar zenith angle (SZA) of $58^{\circ}$, optical path difference (OPD) of $180 \mathrm{~cm}$ and a signal to noise ratio (SNR) of 200. Poker Flat $\mathrm{SZA}=63.61^{\circ}, \mathrm{OPD}=257.143 \mathrm{~cm}$ and $\mathrm{SNR}=100$ ). (Right) Typical CO a-priori VMR profiles used for the retrieval for Ny Alesund (magenta) and Poker Flat (black dashed line).

\section{Results}

A comparison of the partial column densities measured by the FTIRs in molecules $/ \mathrm{cm}^{2}$ from $18 \mathrm{~km}$ to the top of the atmosphere and the model results are shown in Fig. 2 for the period of 2003-2004. The partial column densities measured by the FTIRs are shown by the blue dots. The cyan curve represents the base run from the model, where thermospheric $\mathrm{CO}$ is neglected. Clearly, this run alone cannot reproduce the measurements. The green curve represents the complete run with the thermospheric $\mathrm{CO}$. The model run smoothed by the typical averaging kernels of the FTIR is represented by magenta curve. The smoothing was done according to the formalism described in Rodgers and Connor (2003) and shown in Velazco et al. (2005) for FTIR, model and satellite data comparison of $\mathrm{CO}$ profiles. The smoothed curves represent what the FTIR should "see" if the model were to represent the true CO. FTIR measurements and smoothed model results compare well in the northern hemisphere polar stations. For the Arrival Heights station, the annual variation of $\mathrm{CO}$ is captured by the model qualitatively, however, actual values of the winter maxima are significantly higher in the model results. This might be a result of a wrong estimation of the downward transport in the model. In the mid-latitudes, the model predicts a slight enhancement of the strato-mesospheric $\mathrm{CO}$ columns during winter times over 


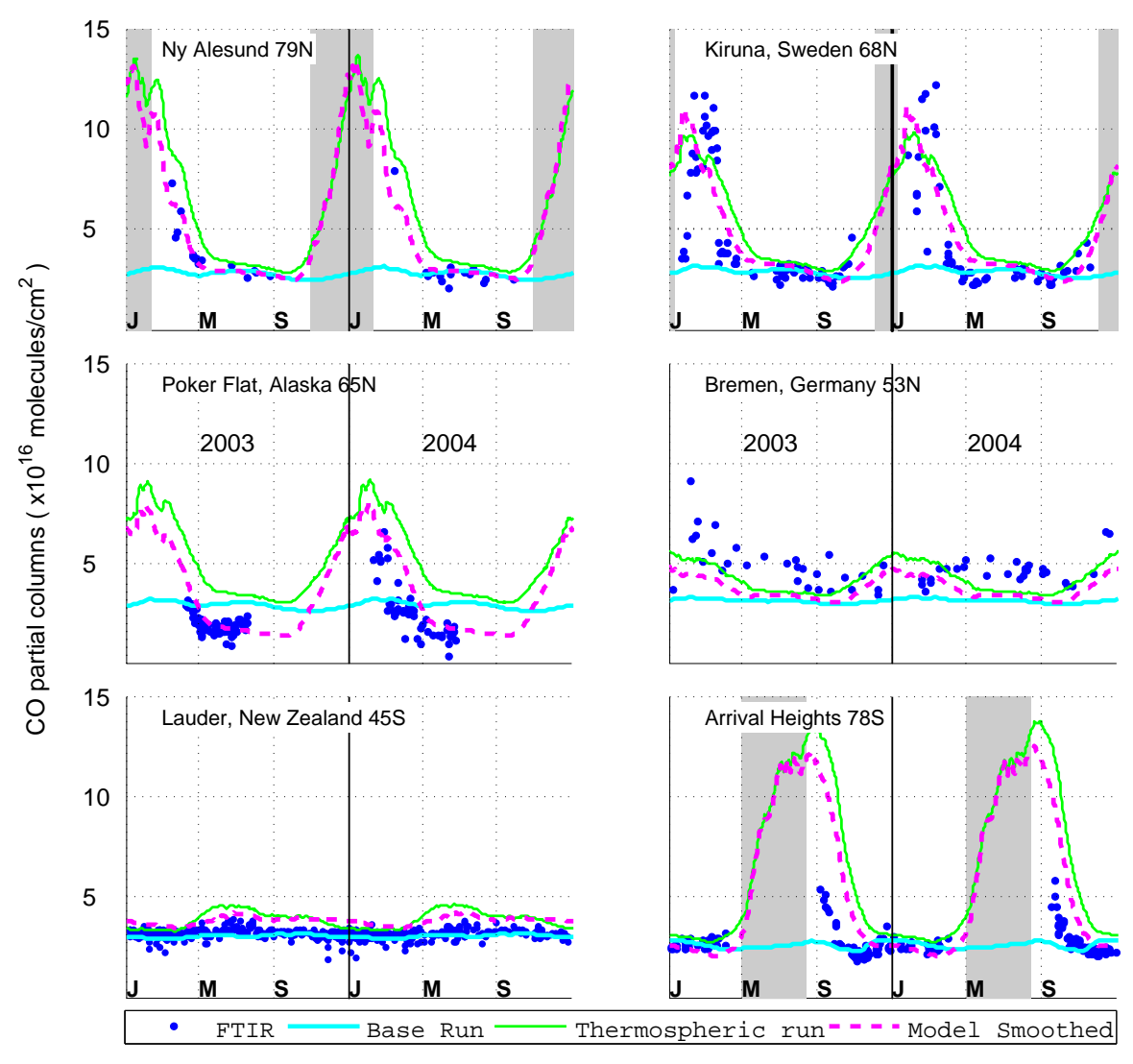

Fig. 2. A comparison of the partial column densities measured by the FTIRs in molecules $/ \mathrm{cm}^{2}$ from $18 \mathrm{~km}$ to the top of the atmosphere and the model results for the period of 2003-2004. Cyan line: base model run without thermospheric CO. Green line: Model run with thermospheric CO. Blue dots: Retrieved columns from the FTIR. Magenta line (dashed): model run smoothed with the averaging kernels of the FTIR according to Rogers and Connor (2003). The shaded area approximately represents polar night at the sites.

Bremen. The model predicts this enhancement to be less pronounced over Lauder.

Long-term time series of $\mathrm{CO}$ partial column densities from $18 \mathrm{~km}$ to the top of the atmosphere measured from FTIR (blue dots) and compared with the model (magenta dashes) are shown in Fig. 3. The measurements were taken from the three polar stations (Ny Alesund and Kiruna from the Arctic and Arrival Heights in Antarctica). The gray shaded areas represent the polar night where solar absorption measurements are not possible. Unlike the seasonal cycles of $\mathrm{CO}$ in the troposphere, the seasonal cycles in the stratomesosphere show very steep gradients, with maximum values occurring in January in the Arctic and in June-July in the Antarctic. As shown by the model (and partially by the measurements), the CO column above $18 \mathrm{~km}$ increases from about $4.0 \times 10^{16}$ molecules $/ \mathrm{cm}^{2}$ in summer to about $14 \times 10^{16}$ molecules $/ \mathrm{cm}^{2}$ in winter (an increase of about 3.5 times). This rapid increase is followed by a rapid decrease as soon as the sun re-appears in spring. Kasai et al. (2005) reported the partial CO columns above $24 \mathrm{~km}$ to be approximately $4.8 \pm 0.55 \times 10^{16}$ molecules $/ \mathrm{cm}^{2}$ from February to April. This report is consistent with the values shown here. The seasonal variation of the strato-mesospheric $\mathrm{CO}$, with maximum values occurring during winter and minimum values in summer is also consistent with the measurements of Forkmann et al. (2003).

Correlation plots and correlation coefficients $(\mathrm{R})$ between the FTIR and model are shown in Fig. 4. Although the correlations of FTIR and model are quite good for high latitudes, where the strato-mesospheric $\mathrm{CO}$ is mainly controlled by downward transport from the thermosphere, the correlation for Kiruna is slightly worse. For Kiruna, horizontal transport and the shearing of the polar vortex possibly play a role as well. Note also that Kiruna is often at the edge of the polar vortex. These factors are not well taken into account in the model. We can tell this by the high strato-mesospheric $\mathrm{CO}$ values measured by the FTIR in contrast to the low values from the model. The correlation plot for Arrival Heights might be better described by a logarithmic fit instead of a linear fit. This seemingly logarithmic distribution may be due to the assumptions of 1) converting all the thermospheric $\mathrm{CO}_{2}$ into $\mathrm{CO}$ and 2) not using a real and smooth $\mathrm{CO}_{2}$ profile in the 


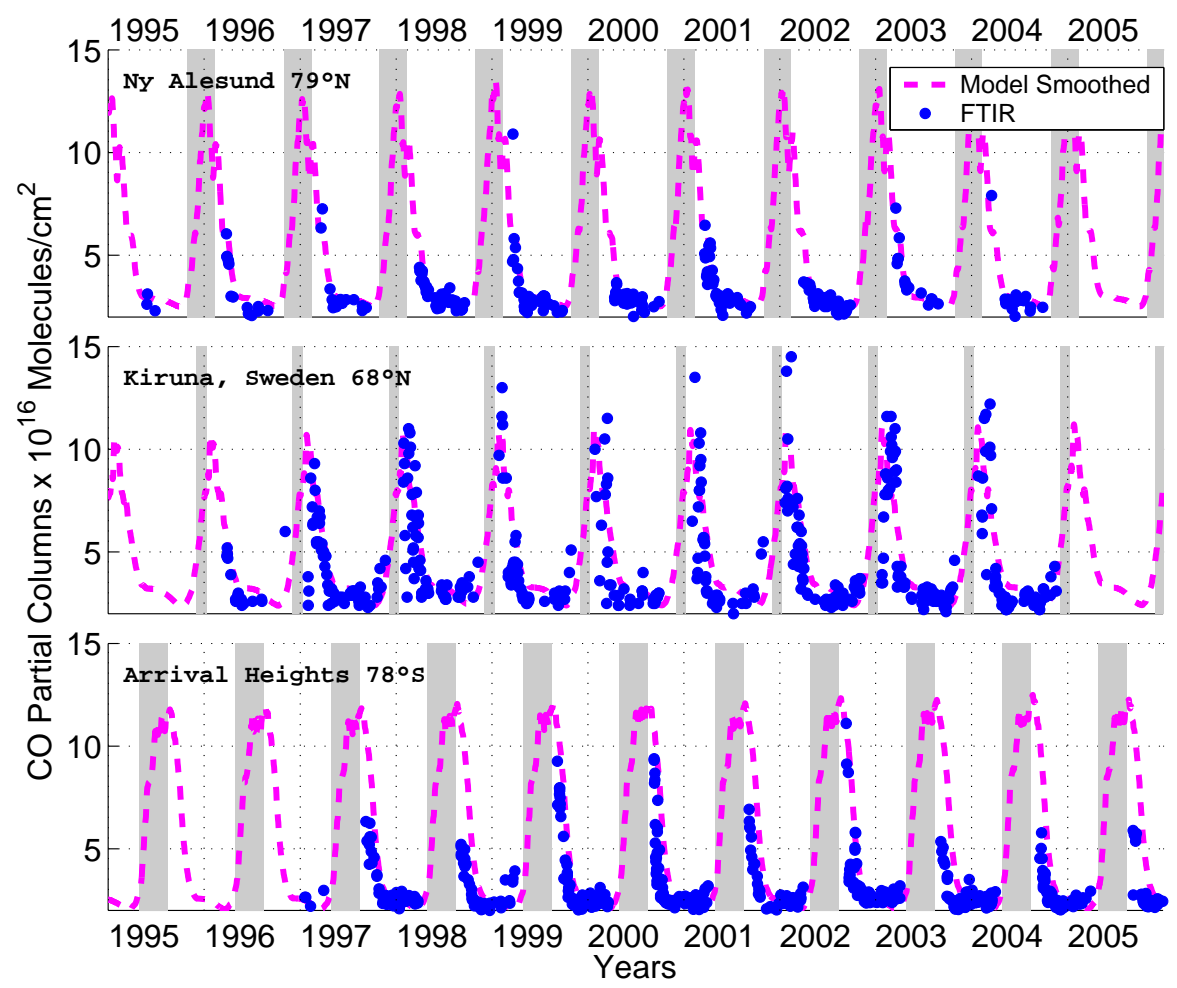

Fig. 3. Long-term FTIR measurements from the three polar stations; Ny Alesund and Kiruna from the Arctic and Arrival Heights in Antarctica (blue dots) compared to the smoothed model data (dashed magenta curves). The measurements and model data are in partial column densities from $18 \mathrm{~km}$ to the top of the atmosphere.

thermosphere. These lead to too much $\mathrm{CO}$ descending from the thermosphere during late fall, then levelling off in winter. Compared to the high latitudes, the correlation coefficients are not so good in mid-latitudes where downward transport of thermospheric $\mathrm{CO}$ is not the most significant contributing factor.

A small enhancement of $\mathrm{CO}$ columns can be observed in late summer from the measurements at the high-latitude stations. This could be seen as a small "bulge" from the average curves from Ny Alesund and Poker Flat in Fig. 5. The average curves were calculated from the whole time series of each station. Values over 15 days were averaged to yield one data point in the curve. The Kiruna and Arrival Heights data exhibit this "summer bulge" for some years (e.g. 1998, 2002 and 2004 in Arrival Heights) but it tends to be smoothed out from the averaging, probably due to the high frequency of varying data points. This summer maximum is very slightly seen in the model, it is much clearer in the "base" model run. In the thermospheric model run, it is superimposed by the much sharper signal of mesospheric CO. This summer maximum in the model is produced by methane oxidation in the stratosphere, which occurs faster in summer. $\mathrm{CO}$ is an intermediate product of methane, it is then slowly transformed into $\mathrm{CO}_{2}$. We speculate that transport processes of $\mathrm{CH}_{4}$ are the major factors that determine the prominence of the sum- mer bulge. However, we could not totally exclude the possibility that the sensitivity of the retrieval methods also play a role here. The average curves also indicate that, the partial column amounts above $18 \mathrm{~km}$ in spring in the $\operatorname{Arctic}\left(79^{\circ} \mathrm{N}\right)$ are generally slightly higher than in the Antarctic $\left(78^{\circ} \mathrm{S}\right)$. Although the data points for the spring months are quite scarce, we speculate for now that this could be due to the subsidence being stronger above Ny Alesund around spring.

Estimates from the model for the strato-mesospheric $\mathrm{CO}$ above Ny Alesund indicates that, generally about 20\%-80\% of the column above $18 \mathrm{~km}$ comes from the stratosphere $(18-26 \mathrm{~km})$, shown on Fig. 6. This estimate is based on the model data for Ny Alesund for one year. In winter, a significant portion of the column comes from above $56 \mathrm{~km}$, i.e., the mesosphere and lower thermosphere. The summer maximum originates in the layer between $18-26 \mathrm{~km}$. It cannot be seen above $56 \mathrm{~km}$. This could be a strong indication that the "summer bulge" detected by the FTIR originates from the stratosphere

The steep gradients of strato-mesospheric $\mathrm{CO}$ seen in the polar regions are not evident in the FTIR data over Lauder $\left(45^{\circ} \mathrm{S}\right)$. shown in Fig. 7. Although there is a strong variability in the columns below $18 \mathrm{~km}$ mostly due to biomass burning (Jones et al., 2001), the strato-mesospheric columns show almost no variability. This dataset confirms that the columns 
CO Partial Columns (Model vs. FTIR)
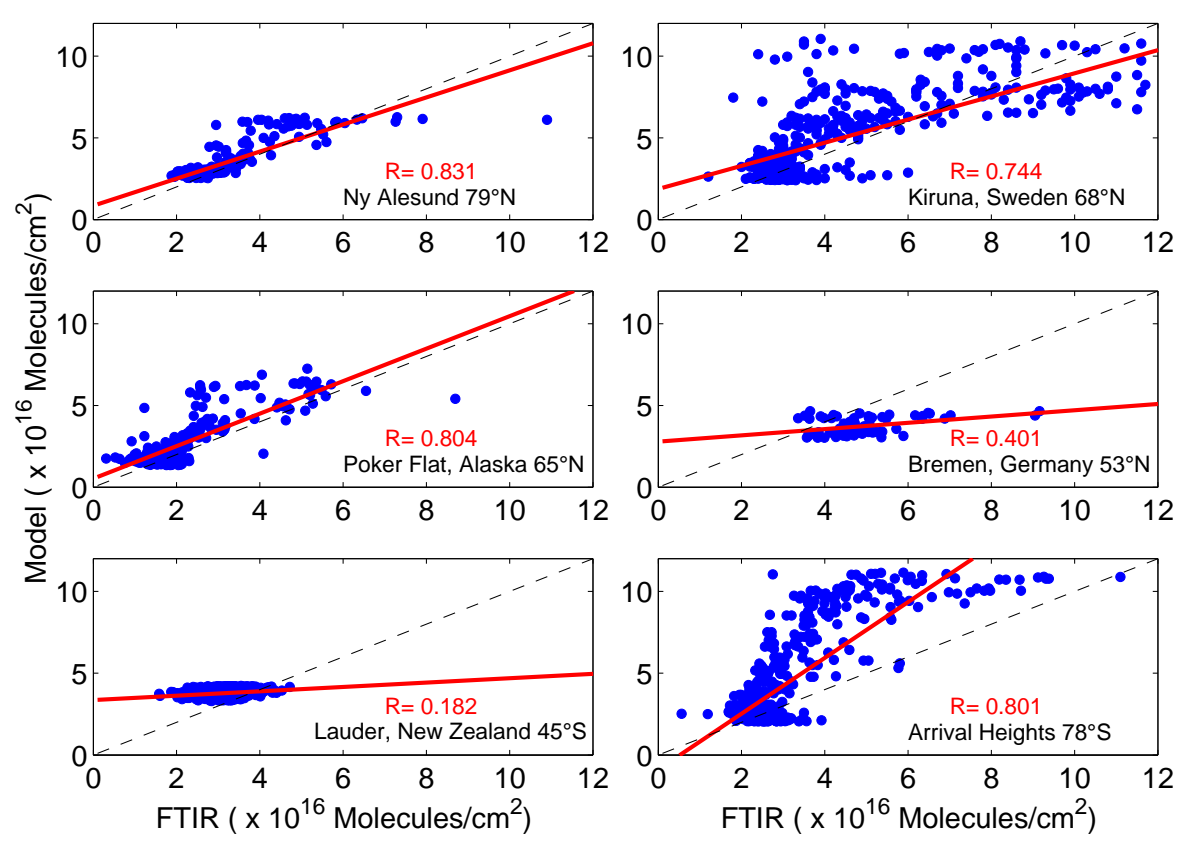

Fig. 4. Correlation plots (model output vs. FTIR data) and the correlation coefficients (R). The whole time series of the FTIR data from each station and the corresponding model output are plotted and calculated for this figure. The red lines represent least squares fits to the points. The black dashed lines represent correlation coefficients of 1.0.

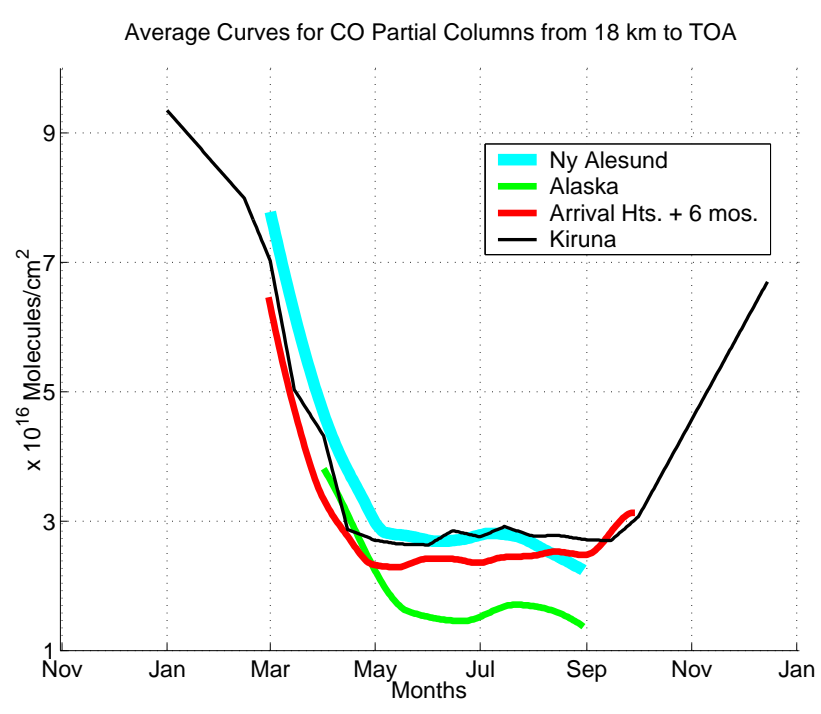

Fig. 5. Average curves calculated from the time series of the 4 Polar stations: Ny Alesund, Poker Flat, Kiruna and Arrival Heights. The summer bulge in July-August can be distinguished from the Poker Flat and Ny Alesund data. The Arrival heights data (shifted by six months) only shows small "lumps" in June and August. The variability in the data in Arrival heights averages out the summer bulge. The average curves were calculated from the whole time series of each station. Values over 15 days were averaged to yield one bin in the curve. below $18 \mathrm{~km}$ have very little or no influence on the columns above $18 \mathrm{~km}$ and that the retrieval could clearly separate both columns, as indicated by the averaging kernels. The only exceptions to the monotonous strato-mesospheric $\mathrm{CO}$ trends in the mid-latitudes are the values measured in the winters of 2002-2003 and 2004-2005 over Bremen (53 $\left.{ }^{\circ} \mathrm{N}\right)$.

\section{Conclusions}

The downward transport of strato-mesospheric CO above $18 \mathrm{~km}$ in the winter polar regions, which is strongly influenced by the meridional circulation, as predicted by Solomon et al. (1985), can be seen in the FTIR data. The same pattern has also been reported in Kasai et al. (2005) using groundbased FTIR and in studies using ground-based microwave instruments (e.g. Aellig et al., 1995; Forkmann et al., 2003). The strong gradient showing a maximum in winter and minimum in summer are well captured by the measurements and verified by the model. We showed in this study that this feature is generally not observed in mid-latitude stations. This is in agreement with the VMR profiles shown by Dupuy et al. (2004) using data from the sub-millimeter radiometer instrument on board the Odin satellite. Although they showed zonal means only for 2 different days (7 August and 18 November 2001), it was shown that the enhancement of strato-mesospheric CO occurs mostly in the high latitude regions. 


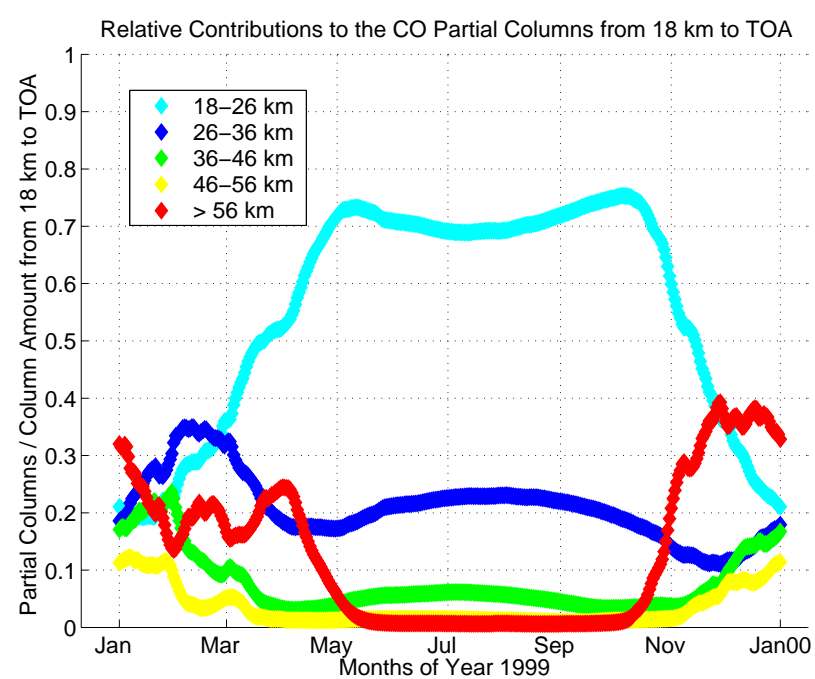

Fig. 6. Relative contributions of each layer to the column above $18 \mathrm{~km}$ calculated from the model. The contributions are calculated from the $\mathrm{CO}$ partial columns coming from a certain layer divided by the total columns above $18 \mathrm{~km}$. These curves indicate where the signal should come from. In winter, most of the CO partial column above $18 \mathrm{~km}$ is dominated by the CO coming from above $56 \mathrm{~km}$ and from the $26-36 \mathrm{~km}$ layer. This is also the time when the downward transport from the mesosphere is strongest. In summer, the column above $18 \mathrm{~km}$ is dominated by $\mathrm{CO}$ at $18-26 \mathrm{~km}$ where $\mathrm{CH}_{4}$ oxidation plays a significant role in the production of $\mathrm{CO}$.

$\mathrm{CO}$ in the mesosphere is influenced by the competition between downward transport from the thermosphere and $\mathrm{OH}$ oxidation. The FTIR measurements show that the pattern of the strato-mesospheric $\mathrm{CO}$ columns for all years in one station are almost similar. We assign this to $\mathrm{CO}$ having a shorter lifetime compared to the downward vertical transport in the mesosphere-stratosphere during the measurement periods. On the other hand, the data from the average curves suggest that, partial column amounts in the Arctic spring are slightly higher than in the Antarctic spring. For now, we speculate that this could be due to the subsidence being stronger in the Arctic than in the Antarctic. However, we still could not say much for the periods with very scarce or no measurements. In winter, the intra-seasonal and inter-annual variability in of mesospheric $\mathrm{CO}$ alone is large, according to Forkmann et al. (2003). From two years of observations, they reported CO columns above $60 \mathrm{~km}$ in the winters (defined as November-March) of 2001-2002 to be twice larger than the previous year. We could not completely confirm this yet from the FTIR data due to lack of observations. Nevertheless, filling in this information gap for the future is another challenge for the FTIR

Comparisons with a global two-dimensional photolysis, chemistry and transport model in the stratosphere and mesosphere were shown. The assumption in the model that all the $\mathrm{CO}_{2}$ in the thermosphere is converted into $\mathrm{CO}$ via photolysis

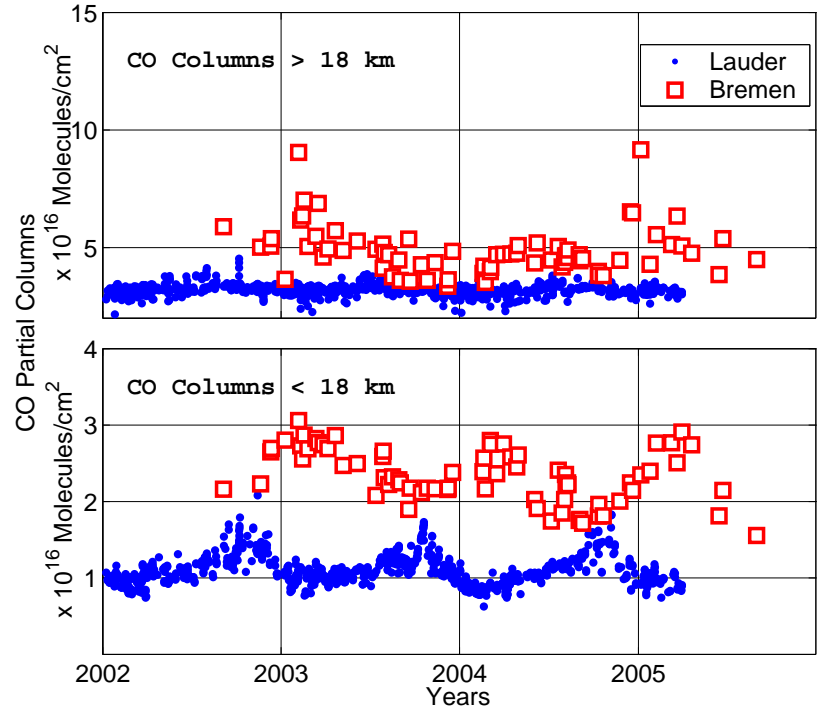

Fig. 7. $\mathrm{CO}$ columns above and below $18 \mathrm{~km}$ from the two midlatitude stations: Bremen $53^{\circ} \mathrm{N}$ (red squares) and Lauder $45^{\circ} \mathrm{S}$ (blue dots).

has been shown to be reasonable for this study. Despite the very simple assumptions in the model, the agreement with the FTIR is quite good, especially in the high latitude regions. According to the model, the production of $\mathrm{CO}$ from $\mathrm{CH}_{4}$ oxidation in the mid to upper stratosphere could result to a signal indicated by the "summer bulge" in the FTIR data seen in Ny Alesund, Poker Flat and occasionally in Kiruna and Arrival Heights. This will be further investigated in another study.

Acknowledgements. V.Velazco wishes to thank Mathias Palm and Björn Martin Sinnhuber for helpful discussions and the anonymous referees for reviewing this work. S. W. Wood acknowledges the New Zealand Foundation for Research Science and Technology and Antarctica New Zealand. I. Kramer, T. Blumenstock and F. Hase gratefully acknowledge the Goddard Space Flight Center for providing temperature and pressure profiles via the auto mailer system and Uwe Raffalski from IRF Kiruna for support of FTIR measurements. Y.Kasai acknowledges Yasuhiro Muaraya (NICT), Akiko Kagawa (Fujitsu FIP), and Tsuyoshi Koshiro (Kyoto University) for the analysis of the FTIR data and useful discussions. We are grateful to the European Commission via the project UFTIR (contract EVK2-2002-000159) and national financial support by the Helmholtz Association within the virtual institute PEP. Part of the work was supported by the DFG CAWSES program with the project SACOSAT.

Edited by: W. Ward 


\section{References}

Chipperfield, M. P.: Multiannual simulations with a threedimensional chemical transport model, J. Geophys. Res., 104, 1781-1805, 1999.

Chipperfield, M. P. and Feng, W.: Comment on: Stratospheric Ozone Depletion at northern mid-latitudes in the 21st century: The importance of future concentrations of greenhouse gases nitrous oxide and methane, Geophys. Res. Lett., 30(7), 1389, doi:10.1029/2002GL016353, 2003.

Clancy, R. T., Muhleman, D. O., and Allen, M.: Seasonal variability of CO in the terrestrial mesosophere, J. Geophys. Res., 89(D6), 9673-9676, 1984.

Clerbaux, C., Coheur, P. F., Hurtmans, D., Barret, B., Carleer, M., Colin, R., Semeniuk, K., McConnell, J. C., Boone, C., and Bernath, P.: Carbon monoxide distribution from ACE-FTS solar occultation measurements, Geophys. Res. Lett., 32, L16S01, doi:10.1029/2005GL022394, 2005.

Dupuy, É., Urban, J., Ricaud, P., et al.: Strato-mesospheric measurements of carbon monoxide with the Odin sub-millimeter radiometer: retrieval and first results, Geophys. Res. Lett., 31, L20101, doi:10.1029/2004GL020558, 2004.

Farmer C. B., Raper, O. F., Robbins, B. D., Toth, R. A., and Muller, C.: Simultaneous spectroscopic measurements of stratospheric species: $\mathrm{O}_{3}, \mathrm{CH}_{4}, \mathrm{CO}, \mathrm{CO}_{2}, \mathrm{~N}_{2} \mathrm{O}, \mathrm{H}_{2} \mathrm{O}, \mathrm{HCl}$ and $\mathrm{HF}$ at northern and southern mid-latitudes., J. Geophys. Res., 86, 5179-5184, 1980.

Forkman, P., Eriksson, P., and Winnberg, A.: Longest ground-based measurements of mesospheric CO, Geophys. Res. Lett., 30(10), 1532, doi:10.1029/2003GL016931, 2003.

Goldsmith, P. F., Litvak, M. M., Plambeck, R. L., and Williams, D. R.: Carbon monoxide mixing ratio in the mesosphere derived from gound based microwave measurements, J. Geophys. Res., 84, 416-418, 1979.

Hase, F.: Inversion von Spurengasprofilen aus hochaufgeloesten bodengebundenen FTIR-Messungen in absorption, Wissenschaftliche Berichte Forschungszentrum Karlsruhe, FZKA 6512, ISSN 0947-8620, 2002.

Hase, F., Hannigan, J. W., Coffey, M. T., Goldman, A., Hpfner, M., Jones, N. B., Rinsland, C. P., and Wood, S. W.: Intercomparison of retrieval codes used for the analysis of high-resolution, ground-based FTIR measurements, J. Quant. Spectrosc. Radiat. Transfer, 87, 25-52, 2004.

Jones, N. B., Rinsland, C. P., Ben Liley, J., Rosen, J.: Correlation of aerosol and carbon monoxide at $45^{\circ} \mathrm{S}$ : Evidence of biomass burning emissions, Geophys. Res. Lett., 28(4), 709-712, 2001.

Kanamitsu, M.: Description of the NMC global data assimilation and forecast system, Wea. Forecast., 4, 335-342, 1989.

Kasai, Y., Koshiro, T., Endo, M., Jones, N. B., Murayama, Y.: Ground based measurement of strato-mesospheric CO by a FTIR spectrometer over Poker Flat, Alaska, Adv. Space Res., 35(11), 2024-2030, doi:10.1016/j.asr.2005.04.099, 2005.

Kinnersley, J. S.: The climatology of the stratospheric THIN AIR model, Quart. J. Roy. Meteorol. Soc., 122, 219-252, 1996.
Künzi, K. F. and Carlson, E. R.: Atmospheric CO mixing ratio profiles determined from ground based measurements of the $\mathrm{J}=1 \rightarrow$ 0 and $\mathrm{J}=2 \rightarrow 1$ emission lines, J. Geophys. Res., 87, 7235-7241, 1982.

Lopez-Valverde, M. A., Lopes-Puertas, M., Marks, C. J., and Taylor, F. W.: Global and seasonal variations in the middle atmosphere carbon monoxide from UARS/ISAMS, Geophys. Res. Lett., 20, 1247-1250, 1993.

Notholt, J., Toon, G., Stordal, F., Solberg, S., Schmidbauer, N., Becker, E., Meier, A., and Sen, B.: Seasonal variations of trace gases in the high Arctic at $79^{\circ} \mathrm{N}, \mathrm{J}$. Geophys. Res., 102(D11), 12 855-12 861, 1997.

Rinsland, C. P., Jones, N. B., Connor, B. J., Logan, J. A., Pougatchev, N. S., Goldman, A., Mucray, F. J., Stephen, T. M., Pine, A. S., Zander, R., Mahieu, E., and Demoulin, P.: Northern and southern hemispheric ground-based infrared spectroscopic measurements of tropospheric carbon monoxide and ethane, J. Geophys. Res., 103(D21), 28 197-28 217, 1998.

Rodgers, C.: Inverse Methods for Atmospheric Sounding: Theory and Practice, Vol. 2, Series on Atmospheric, Oceanic and Planetary Physics, World Sci., River Edge N.J., 2000.

Rodgers, C. D. and Connor, B.: Intercomparison of remote sounding instruments, J. Geophys. Res., 108(D3), 4116, doi:10.1029/2002JD002299, 2003.

Rothman, L., Barbe, A., Benner, D. C., et al.: The HITRAN molecular spectroscopic database : Edition of 2000 including updates through 2001, J. Quant. Spectr. Ra., 82, 5-44, 2003.

Sander, S. P., Friedl, R. R., Golden, D. M., Kurylo, M. J., Huie, R. E., Orkin, V. L., Moortgat, G. K., Ravishankara, A. R., Kolb, C. E., Molina, M. J., and Finlayson-Pitts, B. J.: Chemical Kinetics and Photochemical Data for Use in Atmospheric Studies, Evaluation No. 14, JPL Publication 02-25, Jet Propulsion Lab, Pasadena, CA, 2003.

Sinnhuber, M., Burrows, J., Künzi, K. F., Chipperfield, M. P., Jackman, C. H., Kallenrode, M. B., and Quack, M.: A model study of the impact of magnetic field structure on atmospheric composition during solar proton events, Geophys. Res. Lett., 30(15), 1818, doi:10.1029/2003GL017265, 2003.

Solomon, S., Garcia, R. R., Olivero, J. J., Bevilacqua, R. M., Schwartz, P. R., Clancy, R. T., and Muhleman, D. O.: Photochemistry and transport of Carbon Monoxide in the middle atmosphere, J. Atmos. Sci., 42(10), 1072-1083, 1985.

Velazco, V., Notholt, J., Warneke, T., Lawrence, M., Bremer, H., Drummond, J., Schulz, A., Krieg, J., and Schrems, O.: Latitude and Altitude Variability of Carbon Monoxide in the Atlantic Detected from Ship-borne Fourier Transform Spectrometry, Model and Satellite Data, J. Geophys. Res., 110, D09306, doi:10.1029/2004JD005351, 2005.

WMO (World Meteorological Organization): Scientific Assessment of Ozone Depletion: 2002, Global Ozone Research and Monitoring Project, Report No. 47, 498 pp., Geneva, 2003.

Zander, R., Leclercq, H., and Kaplan, L. D.: Concentration of carbon monoxide in the upper stratosphere, Geophys. Res. Lett., 8, 365-368, 1981. 